\title{
Successful Surgical Correction of Anomalous Origin of the Left Pulmonary Artery from the Ascending Aorta in a 16-Year-Old Boy with Fallot's Tetralogy
}

\author{
Deshbandhu Sharma, Rajnish Pathania, Sudhir Mehta, Rajesh Chopra \\ Department of CTVS, IGMC, Shimla, Himachal Pradesh, India \\ ORCID: \\ Deshbandhu Sharma: https://orcid.org/0000-0001-9306-7367 \\ Rajnish Pathania: https://orcid.org/0000-0002-2585-2846 \\ Sudhir Mehta: https://orcid.org/0000-0002-1028-732X \\ Rajesh Chopra: https://orcid.org/0000-0002-6519-6441
}

\section{Abstract}

Tetralogy of Fallot (TOF) is a frequently encountered congenital heart defect, and the detailed diagnostic criteria are well established. There may be other anomalies associated with TOF, but the anomalous origin of the left pulmonary artery (LPA) from the ascending aorta (AOPA) is a rare one. The diagnosis of this anomaly, which may be mistaken for the absence of the LPA, should be made in early life to avoid unilateral pulmonary hypertension and also for appropriate surgical planning. We are reporting a case of a 16-year-old child, with the diagnosis of TOF associated with anomalous origin of the LPA from the AOPA who underwent a one-stage surgical correction of this anomaly.

Keywords: Anomalous origin, pulmonary artery, tetralogy of fallot

\section{INTRODUCTION}

Pulmonary anomalies in the form of underdevelopment are typical in individuals with complex forms of Tetralogy of Fallot (TOF). Rare pulmonary malformations associated with TOF may be in the form of anomalous origin of right or left pulmonary artery (LPA) from the ascending aorta (AOPA), descending aorta, or aortic arch vessels. It is well known that when occurring as an isolated lesion, the right pulmonary artery (RPA) branch is usually involved, and when associated with TOF, the LPA is more commonly affected. ${ }^{[1]}$ Clinical presentation of such pathologies could be a challenge for routine diagnostics, therapeutic strategy plans, and the final results. Most of the cases of TOF associated with anomalous origin of LPA reported in the literature were infants; the case described here presented at 16 years of age with TOF and anomalous origin of LPA from AOPA.

Submission: 22-03-2019 Revision: 28-05-2019 Accepted: 09-07-2019

Published Online: 13-02-2020

\begin{tabular}{|l|l|}
\hline \multicolumn{2}{|c|}{ Access this article online } \\
\hline Quick Response Code: & Website: \\
\hline & http:/www.ijcva.com \\
\hline & \\
\hline
\end{tabular}

\section{Case Report}

A 16-year-old male child with a body surface area (BSA) of $0.95 \mathrm{~m}^{2}$ presented with cyanosis since 2 months of age, progressive dyspnea, and easy fatigability with cyanotic spells between 8 and 12 months of age.

On examination, there was cyanosis, single and loud $\mathrm{S}_{2}$, a Grade III harsh ejection systolic murmur at the left third intercostal space (ICS) with Grade III continuous murmur at the left $2^{\text {nd }}$ ICS, and interscapular area. Preoperative $\mathrm{SpO}_{2}$ was $82 \%$. Electrocardiogram showed normal sinus rhythm, right axis deviation, and biventricular hypertrophy. Chest X-ray revealed right ventricular type apex, left lung field plethoric with prominent

Address for correspondence: Dr. Rajnish Pathania, Department of CTVS, IGMC, Shimla, Himachal Pradesh, India. E-mail: rajnishpathania@msn.com

This is an open access journal, and articles are distributed under the terms of the Creative Commons Attribution-NonCommercial-ShareAlike 4.0 License, which allows others to remix, tweak, and build upon the work non-commercially, as long as appropriate credit is given and the new creations are licensed under the identical terms.

For reprints contact: reprints@medknow.com

How to cite this article: Sharma D, Pathania R, Mehta S, Chopra R. Successful surgical correction of anomalous origin of the left pulmonary artery from the ascending aorta in a 16-year-old boy with Fallot's tetralogy. Int J Cardiovasc Acad 2020;6:26-8. 
LPA, and oligemic right lung field [Figure 1a]. Echocardiogram showed situs solitus, levocardia, large subaortic ventricular septal defect (VSD) with aortic override, severe infundibular stenosis with hypoplastic main pulmonary artery (MPA) 7-8 mm, RPA $12 \mathrm{~mm}$, LPA origin from MPA not visualized with suspicion of ascending aortic origin, and normal right ventricle (RV)/ left ventricle systolic function. Cardiac catheterization showed nonrestrictive VSD, with aortic over-ride (50\%), RV angiogram showing almost simultaneous filling of the AOPA, MPA continuing as RPA only [Figure 1b], and opacification of the LPA from aorta. Pressure in ascending Aorta was 100/60 mmHg, RV- 98/18 mmHg. Individual pressure in RPA and LPA not available as they could not be hooked. Aortogram revealed a LPA originating from the AOPA [Figure 1c], RPA $12 \mathrm{~mm}$, and LPA $13 \mathrm{~mm}$. McGoon ratio was 1.6 and Nakata index 252. Z score was zero for both LPA and RPA and $<3$ for MPA as per standard nomogram for this BSA. Computed tomography angiography showed VSD, overriding of aorta, MPA hypoplastic $(7.6 \mathrm{~mm})$, LPA arising from arch of aorta (LPA $12 \mathrm{~mm}$ ), RPA $10 \mathrm{~mm}$, right ventricular hypertrophy, enlargement of the left atrium, and left ventricular [Figure 1d].

Complete correction was accomplished using cardiopulmonary bypass. The LPA originated at the junction of AOPA and arch opposite the origin of innominate artery [Figure 2a]. MPA was hypoplastic ( $8 \mathrm{~mm})$, RPA (10-12 mm) and LPA (12-14 mm in size). LPA was dissected and mobilized up to the first branch and separated from aorta before applying cross clamp [Figure $2 \mathrm{~b}$ and $\mathrm{c}$ ]. Disconnected LPA was anastamosed to the MPA along with trans-annular pericardial patch [Figure 2d]. The
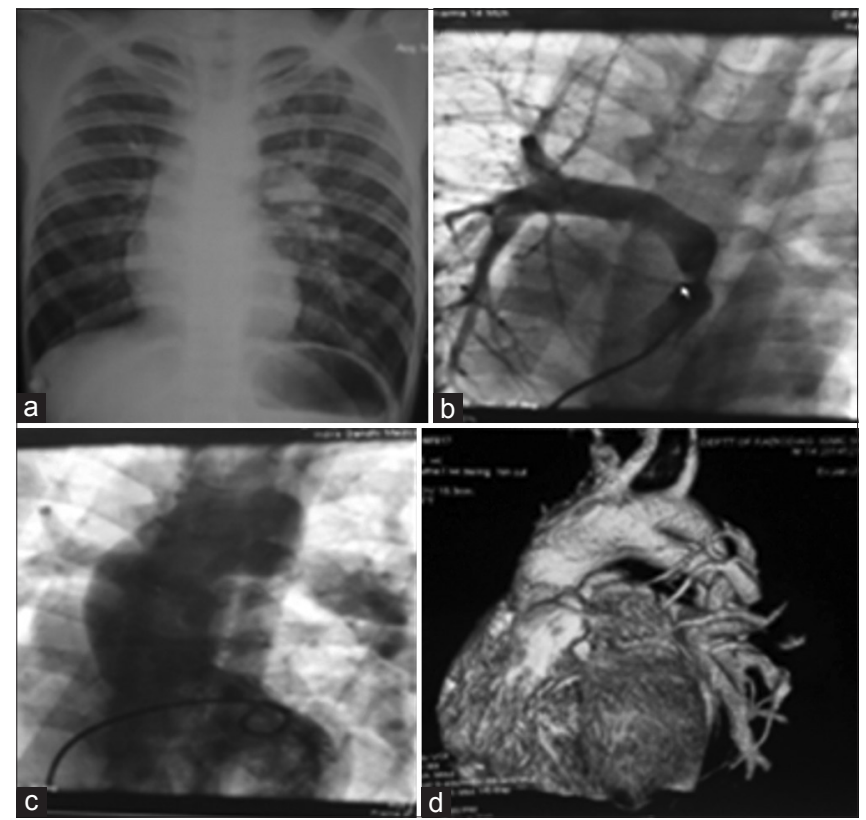

Figure 1: (a) Chest X-ray revealed right ventricular type apex, left lung field plethoric with prominent left pulmonary artery, and oligemic right lung field, (b) main pulmonary artery leading to right pulmonary artery only, (c) aortogram showing origin of the left pulmonary artery from aorta, (d) computed tomography angiography confirming origin of left pulmonary artery patient tolerated the procedure well. Bypass time was $3 \mathrm{~h} 14 \mathrm{~min}$ and cross-clamp time $2 \mathrm{~h} 8 \mathrm{~min}$. Postoperative $\mathrm{SpO}_{2}$ was $94 \%$ and extubation was done after $6 \mathrm{~h}$ of surgery and postoperative period was uneventful. He was discharged on postoperative day 8 in satisfactory condition. Child is doing well after surgery and echo at 1 year of follow-up showed mild TR with TR gradient of $25 \mathrm{mmHg}$ with mild pulmonary regurgitation.

\section{Discussion}

The main pulmonary trunk is derived from the truncus arteriosus as a result of its septation. In defective septation of the truncus arteriosus, pulmonary (sixth) arch will remain connected to the aorta proximally. Involutionary changes occurring in the arch determine the final defect. If the proximal segment remains patent and the distal segment involutes, there will be anomalous origin of a pulmonary artery from the AOPA.$^{[2]}$ Anomalous origin of one pulmonary artery from the AOPA is a rare congenital cardiac malformation that was first described by Fraentzel ${ }^{[3]}$ in 1868 . Prifti et al.$^{[4]}$ reviewed the age, associated malformations, and surgical procedure undertaken during the past 30 years, and major associated heart defects were identified in $28.7 \%$ patients. The most frequently found cardiac malformation was the TOF in $11.8 \%$ of cases. ${ }^{[4]}$

The natural progression of AOPA includes early pulmonary hypertension, infantile respiratory distress, and congestive heart failure. Early repair is preferred to avoid pulmonary hypertension, congestive heart failure, and irreversible pulmonary vascular disease. Therefore, surgical treatment is recommended as soon as the diagnosis is confirmed during the neonatal and infant period. ${ }^{[5]}$ Most repairs require the use of an artificial or homologous conduit due to inadequate vasculature length for the connection between the aberrant pulmonary

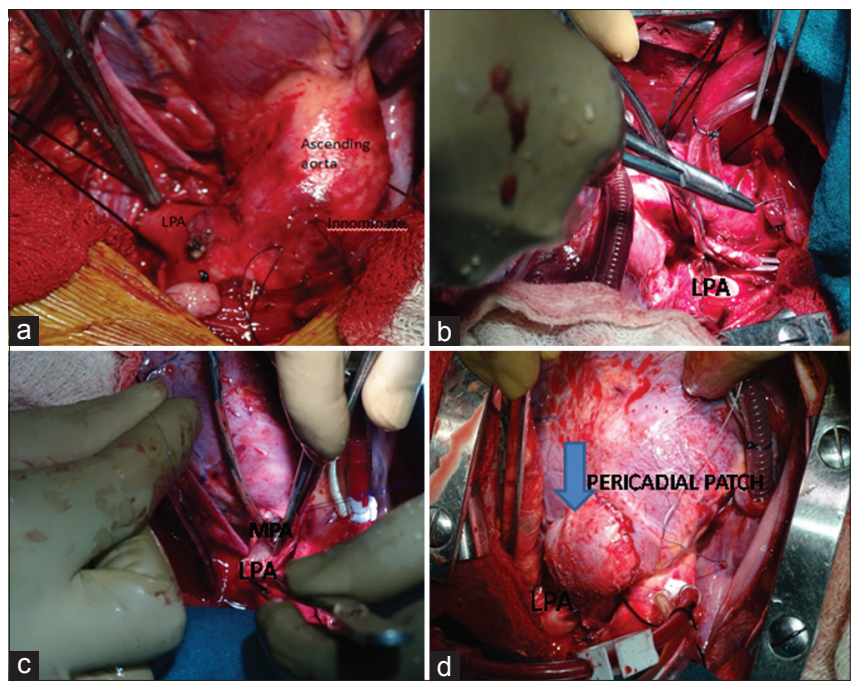

Figure 2: (a) Left pulmonary artery originating at the junction of ascending aorta and arch opposite the origin of innominate artery, (b) left pulmonary artery dissected, divided, and aortic end closed before aortic cross-clamp, (c) posterior anastomosis of main pulmonary artery and left pulmonary artery, (d) left pulmonary artery along with transannular patch 
artery and the MPA. However, complications involving these grafts include anastomotic stenosis and age-dependent replacement of the conduits during the follow-up. In the present case, LPA could be anastomosed to MPA along the transannular patch without any conduit due to the adequate length of LPA.

Careful evaluation of echocardiography and angiogram should be done in patients of TOF with suspected absence of anomalous origin ofLPA. Based on these possibilities, it is essential that in cases of TOF with a nonvisualized LPA, its aortic origin should be searched for. Attempted total correction in a case of TOF with LPA from the arch of the aorta, described by Czarnecki et al. ${ }^{[6]}$ ended in surgical disaster because the anomalous LPA was not recognized before surgery.

In 1989, six cases of anomalous origin of LPA were described by Fong et al., ${ }^{[7]}$ and two of them were associated with TOF. It should be mentioned that two of these patients, with an approximate age of 2 years, died soon after operation, and in the autopsy left pulmonary hypertension was evident. ${ }^{[1]}$

\section{Conclusion}

We suggest that AOPA is a very rare entity, which should be kept in mind in every patient under investigation with a clinical diagnosis of TOF, particularly in cases where the LPA appears to be absent. Surgical correction should be done soon after diagnosis if pulmonary hypertension is to be avoided. If anomalous origin of pulmonary artery diagnosed preoperatively, it is possible to do a total correction of TOF along with anastomosis of LPA to MPA even when the patient presents late.

\section{Declaration of patient consent}

The authors certify that they have obtained all appropriate patient consent forms. In the form the patient(s) has/have given his/her/their consent for his/her/their images and other clinical information to be reported in the journal. The patients understand that their names and initials will not be published and due efforts will be made to conceal their identity, but anonymity cannot be guaranteed.

\section{Financial support and sponsorship}

Nil.

\section{Conflicts of interest}

There are no conflicts of interest.

\section{References}

1. Amaral F, Teixeira MA, Granzotti JA, Manso PH, Vicente WV. Anomalous origin of the left pulmonary artery from the ascending aorta. Successful surgical correction in an infant with fallot's tetralogy. Arq Bras Cardiol 2002; 79:538-43.

2. Morgan JR. Left pulmonary artery from ascending aorta in tetralogy of fallot. Circulation 1972;45:653-7.

3. Fraentzel O. A case of abnormal communication of the aorta with the pulmonary artery. Arch Pathol Anat 1868;43:420-6.

4. Prifti E, Crucean A, Bonacchi M, Bernabei M, Leacche M, Murzi B, et al. Postoperative outcome in patients with anomalous origin of one pulmonary artery branch from the aorta. Eur J Cardiothorac Surg 2003;24:21-7.

5. Liu Y, Cheng L, Qian X, Zhu H, Duan W, Yu S, et al. Surgical correction of anomalous origin of one pulmonary artery without grafts in infants. J Card Surg 2015;30:85-91.

6. Czarnecki SW, Hopeman AR, Child PL. Tetralogy of fallot with aortic origin of the left pulmonary artery: Radiographic and angiocardiographic considerations. Report of a case. Dis Chest 1964;46:97-101.

7. Fong LV, Anderson RH, Siewers RD, Trento A, Park SC. Anomalous origin of one pulmonary artery from the ascending aorta: A review of echocardiographic, catheter, and morphological features. Br Heart J 1989;62:389-95. 